\title{
Topical Cyclosporine in Treatment of Post-LASIK Symptomatic Dry Eye
}

\author{
Muhammad Saeed lqbal ${ }^{1}$, Kanwal Latif ${ }^{2}$ \\ ${ }^{1-2}$ Department of Ophthalmology, Sir Syed College of Medical Sciences and Hospital, Karachi
}

\begin{abstract}
Purpose: To determine the role of $0.05 \%$ topical cyclosporine $A(C s A)$ in treatment of symptomatic dry eye after LASIK (Laser-Assisted in Situ Keratomileusis).

Study Design: Interventional Case Series.

Place and Duration of Study: Ophthalmology Department, Sir Syed Hospital, Karachi, from July 2018 to Dec. 2019.

Methods: Seventy-five patients who underwent LASIK for myopic refractive error and presented with symptomatic dry eye and showed no response to artificial tears therapy after 1 month of LASIK were selected. The patient had ablation zone diameter of $6 \mathrm{~mm}$ and flap diameter was $8.5 \mathrm{~mm}$ to $9 \mathrm{~mm}$. Cyclisporine A $0.05 \%$ ophthalmic preparation was added to treatment regimen and response was observed at 1, 3 and 6 months. OSDI (Ocular Surface Disease Index) scores, Tear film break up time (TBUT), Schirmer's test (ST) values and Best Corrected Visual Acuity (BCVA) were recorded to analyze the treatment response at each visit. The statistical interpretation was done by using SPSS version 21. To interpret the correlation between pre-treatment and 6 month post treatment, Paired sample T test was applied with $95 \%$ Confidence Interval; $\mathrm{Cl}$ and $\mathrm{p}$-value of $\leq 0.05$.
\end{abstract}

Results: The mean post-LASIK OSDI score of enrolled patients was $54.25 \pm 10.81$. After 6 months of treatment mean OSDI score was improved to $21.05 \pm 5.13(p<0.001)$. Post-LASIK mean ST value was $5.2 \pm 1.2 \mathrm{~mm}$ and mean TBUT value was $5.6 \pm 1.3$ seconds, which changed to $9.8 \pm 1.0 \mathrm{~mm}$ and $8.9 \pm 1.1$ seconds respectively. BCVA improved from Log MAR $0.14 \pm 0.09$ to $0.01 \pm 0.03(p<0.001)$.

Conclusion: Topical CsA $0.05 \%$ was effective in alleviating the symptoms of post-LASIK dry eye.

KEY Words: LASIK, Dry eye, Ocular Surface Disease Index Score, Cyclosporine A.

How to Cite this Article: lqbal MS, Latif K. Topical Cyclosporine in Treatment of Post-LASIK Symptomatic Dry Eye. Pak J Ophthalmol. 2020; 36 (4): 381-385.

Doi: https://doi.org/10.36351/pjo.v36i4.1078

\section{INTRODUCTION}

LASIK surgery is FDA approved and a widely acceptable procedure throughout the world for

Correspondence: Kanwal Latif

Department of Ophthalmology, Sir Syed College of Medical

Sciences and Hospital, Karachi

Email: kanwallatif@hotmail.com

Received: June 12, 2020

Accepted: July 16, 2020 correction of myopia, hypermetropia and astigmatism ${ }^{1}$. Although it is safe and effective, symptoms of postLASIK dry eye, which is the most commonly reported complaint of patients, often makes final outcomes of LASIK unpredictable ${ }^{2}$. A study reported that dry eye was responsible for $19 \%$ of referrals to the cornea service in a tertiary care hospital due to nonsatisfaction with the results after LASIK ${ }^{3}$.

The pathophysiology of post-LASIK dry eye still remains arguable but iatrogenic damage to corneal nerve plexus is the main reason proposed by researchers. Other suggested mechanisms include 
inadvertent damage to conjunctival goblet cells during flap-creation, post-operative inflammation and tearfilm instability due to post-LASIK corneal re-shaping. ${ }^{4}$ Environmental factors such as sitting in room with chilled air conditioning, facing towards fans, windy conditions etc. and prolonged use of visual display terminals (VDTs) may also contribute to the exacerbation of symptoms in post-operative period. ${ }^{5}$

Dry eye related ocular complaints are fairly common among patients presenting in ophthalmic clinics. Due to diverse etiology and poorly recognized pathogenesis, its management always remains a challenge among ophthalmologists and researchers. ${ }^{6}$ As LASIK predisposes an individual towards worsening of dry eye, identifying patients at risk is the most crucial step in pre-operative evaluation. ${ }^{7}$ Patients with symptomatic dry eye may present with minimal to intense foreign body sensation, grittiness, photophobia, ocular discomfort and blurred vision. The hypothesized mechanisms for these symptoms are tear-film instability and hyper-osmolarity, inflammation and damage to the ocular surface. ${ }^{8}$

The conventional regimen of using artificial lubricants stabilizing the pre-corneal tear-film is the first choice for post-LASIK dry eye. Though majority of patients do well with lubricating eye drops, some still require another regimen that is based on antiinflammatory property. Topical steroids always remain beneficial in treating post-LASIK dry eye but their well-known adverse ocular effects make them undesirable for longer use. ${ }^{4}$

Topical CsA acts as an efficient anti-inflammatory agent in dry eyes because it decreases inflammation, increases the density of goblet cells and also increases the tear production. ${ }^{9}$ Additionally, it improves the corneal sensitivity by a suggested mechanism of regenerating corneal nerve axons. ${ }^{10}$

This case series aimed to assess the effects of $0.05 \%$ topical CsA on symptomatic post-LASIK dry eye.

\section{METHODS}

This study was performed at Ophthalmology department, Sir Syed Hospital Karachi from January 2017 to July 2019. Study approval was given by the Hospital Ethical Review Committee and consent was taken from all the patients. Seventy-five patients presenting with post-operative dry eye were selected. They were graded as moderate to severe according to
OSDI scores based on a validated OSDI questionnaire. Patients who had dry eye even after the use of lubricants for one month after LASIK were included. They all had undergone un-eventful bilateral LASIK for correction of myopia and were unresponsive to initial artificial tears therapy. The exclusion criteria for LASIK patients were: 1) Severe dry eye 2) Corneal ectasias; 3) media opacities such as cataract and corneal scarring; 4) associated systemic and ocular diseases; 5) any previous ocular surgical procedure; and 6) pregnancy and lactation. The excimer laser system used for myopic LASIK was Alcon Wavelight ${ }^{\circledR}$ EX500 and a superiorly hinged flap was created by Hansatome microkeratome. The diameter of ablation zone was $6 \mathrm{~mm}$ in all cases and flap diameter was $8.5 \mathrm{~mm}$ to $9 \mathrm{~mm}$. Any patient who lost his/her follow-up during study period was also excluded. All patients were treated with topical CsA $0.05 \%$ and were advised to fill the OSDI questionnaire at each visit. The OSDI score grading was as follows: Normal: 0-12 points, mild: $13-22$ points, moderate: $23-32$ points and severe: 33-100 points. $^{11}$ BCVA measurement with ETDRS chart, slit-lamp biomicroscopic anterior segment examination, TBUT and Schirmer's test (ST) were performed prior to and after the treatment. ST-1 value of $<10 \mathrm{~mm}$ and TBUT of $<10$ seconds was considered abnormal. Topical CsA $(0.05 \%)$ was prescribed 4 times a day with artificial tears eye drops as needed. Patients were followed at one, three and six months. At each follow-up patient's BCVA, OSDI scores, ST and TBUT were assessed. Patients who reported symptomatic relief and showed improvement in OSDI scores as compared to baseline values were advised to taper topical CsA two times in a day. Treatment was discontinued if OSDI scores became normal or mild and ST and TBUT values were improved. Final values were recorded for analysis at the end of 6 months.

The statistical analysis of quantitative values (age, BCVA, OSDI scores, ST and TBUT) and qualitative values (gender) was done by using the Statistical Package for Social Sciences (SPSS) software version 21. Mean with standard deviation (for quantitative variables) and frequency and percentage (for gender) were computed. To interpret the correlation between pre-treatment and 6 month end treatment results, Paired sample $\mathrm{T}$ test was applied with $95 \%$ Confidence Interval (CI) and $p$-value of $\leq 0.05$ was considered significant. 
Table 1: Pre-treatment and Post-treatment Findings.

\begin{tabular}{|c|c|c|c|c|c|c|}
\hline Parameters & $\begin{array}{l}\text { Pre-treatment } \\
\text { Mean } \pm \text { SD }\end{array}$ & $\begin{array}{c}\text { Post-treatment } \\
\text { at } 1 \text { Month } \\
\text { Mean } \pm \text { SD }\end{array}$ & $\begin{array}{c}\text { Post-treatment } \\
\text { at } 3 \text { Months } \\
\text { Mean } \pm \text { SD }\end{array}$ & $\begin{array}{c}\text { Post-treatment } \\
\text { at } 6 \text { Months } \\
\text { Mean } \pm \text { SD }\end{array}$ & $\begin{array}{c}\text { Mean } \\
\text { Change }\end{array}$ & p-value \\
\hline ODSI score & $54.25 \pm 10.81$ & $46.12 \pm 9.31$ & $33.40 \pm 7.88$ & $21.05 \pm 5.13$ & $33.19 \pm 9.16$ & $<0.001$ \\
\hline $\mathrm{ST}(\mathrm{mm})$ & $5.2 \pm 1.2$ & $6.4 \pm 0.8$ & $8.6 \pm 0.7$ & $9.8 \pm 1.0$ & $-4.16 \pm 1.18$ & $<0.001$ \\
\hline TBUT (seconds) & $5.6 \pm 1.3$ & $6.3 \pm 1.4$ & $7.5 \pm 1.2$ & $8.9 \pm 1.1$ & $-3.29 \pm 0.96$ & $<0.001$ \\
\hline BCVA (Log MAR) & $0.14 \pm 0.09$ & $0.08 \pm 0.06$ & $0.05 \pm 0.05$ & $0.01 \pm 0.03$ & $0.126 \pm 0.094$ & $<0.001$ \\
\hline
\end{tabular}

\section{RESULTS}

Mean pre-LASIK myopic refractive error was $5.79 \pm$ $1.9 \mathrm{D}(-2.25 \mathrm{D}$ to $-9.50 \mathrm{D})$ Mean age of the subjects was $32.39 \pm 5.6$ years $(23-43$ years $)$. The study included $54.7 \%$ females $(\mathrm{n}=41)$ and $45.3 \%$ males $(\mathrm{n}$ $=34$ ). The mean post-LASIK OSDI score which had been considered as pre-treatment score was $54.25 \pm$ 10.81. At the end of six month mean OSDI score changed to $21.05 \pm 5.13$ with statistically significant improvement $(p<0.001)$. See details of ST, TBUT, BCVA and OSDI scores in table 1. All the patients reported an overall improvement in their quality of vision at the end of follow-up. Despite improvement in parameters, patients were not satisfied in initial three months of treatment as symptoms became mild but did not ameliorate fully. After six months, majority of patients were subjectively improved and satisfied as compared to their initial complaints.

\section{DISCUSSION}

Refractive surgeons face various complaints after LASIK but dry eye related problems are by far the most common. Virtually every post-LASIK patient presents with some degree of dry eye in the follow-up period but incidence varies widely with 40-59\% reporting at 1 month and $10-40 \%$ at 6 months. ${ }^{6,12}$ Majority of patients attain 20/20 vision but the drastic effects of dry eye on quality of vision leads to significant discontentment and annoyance among patients as well as the concerned surgeons. As the Asian population is more prone to develop postLASIK dry eye (28\% as compared to Caucasian race) ${ }^{13}$ identifying this risk factor prior to successful LASIK is the most pivotal step for a refractive consultant working in this territory.

The study had included those post-LASIK subjects who had no symptoms pre-operatively but developed severe dry eyes after 1 month of myopic LASIK correction. Shoja ${ }^{14}$ and Nassaralla et $\mathrm{al}^{15}$ have found that even patients who were pre-operatively asymptomatic, may experience irritating dry eye symptoms in their follow-up period and severity is correlated with ablation depth. De Paiva et al reported that the relative risk (RR) of dryness per diopter of myopia was 0.88 and it also depends on the depth of ablation and combined ablation depth and flap creation (RR $1.01 / \mu \mathrm{m}) .{ }^{16}$

In this study, the procedure of myopic LASIK ablation was preceded by cutting a superior-hinged flap (a lamellar flap remained attached at the upper cornea) which might be considered as another factor for developing dry eyes. Donnenfeld ${ }^{17}$ and Feng et $\mathrm{al}^{18}$ suggested that symptomatic post-LASIK dry eye may depend on hinge position as the hinge provides a preserved path for corneal nerves. Various trials supported the fact that superior-hinge flaps have a greater susceptibility of damaging corneal nerves as compared to nasal-hinge flaps, and can cause significant dry eyes in early post-LASIK period. ${ }^{19,20}$

Although CsA is not the first choice among refractive specialists, it is usually reserved for unresponsive cases. Various clinical trials have favored the beneficial effects of topical CsA on LASIK induced dry eyes. ${ }^{21,22}$ In this study, patients experienced distressing symptoms of dry eye with OSDI scores of 54.25 (severe grade) and abnormal ST values of $5.2 \mathrm{~mm}$ and TBUT of 5.6 seconds. They were non-responsive to artificial tear therapy but after commencement of topical CsA OSDI scores improved to 21.05 (mild grade), ST and TBUT values increased to $9.8 \mathrm{~mm}$ and 8.9 seconds respectively with marked subjective improvement. Kanellopoulos has also evaluated the efficacy of topical CsA and reported that post-LASIK OSDI score was 52.51, ST value of 4.5 $\mathrm{mm}$ and TBUT of 6.5 seconds which effectively changed to 23.03, $8.2 \mathrm{~mm}$ and 7.6 seconds respectively. ${ }^{23}$ The study published by Kang and $\mathrm{Kim}^{21}$ also proved the clinical efficacy of the drug in improving the dry eye parameters in patients of LASIK refractive surgery. Salib et al has observed that LASIK outcomes were more successful in topical CsA 
treated group as compared to treatment with artificial tears. ${ }^{24}$

Mean BCVA showed significant change of Log MAR 0.12 at the end of treatment. Ursea and colleagues also supported the fact that visual recovery was hastened by using CsA $0.05 \%$ and majority of their patients attained the desired results. ${ }^{25}$

Limitation of our study was the small sample size and single center of study.

\section{CONCLUSION}

Topical CsA treatment regimen is a good option to treat dry eye symptoms in resistant cases and is an efficacious adjunct to conventional tear supplementation.

\section{Ethical Approval}

The study was approved by the Institutional review board/Ethical review board.

\section{Conflict of Interest}

Authors declared no conflict of interest.

\section{REFERENCES}

1. Agarwal S, Thornell E, Hodge C, Sutton G, Hughes P. Visual outcomes and higher order aberrations following LASIK on eyes with low myopia and astigmatism. Open Ophthalmol J. 2018; 12: 84-93.

2. Fatima K, Saddique Z, Akram SN, Furqan A. Lasik; effect on tear film stability. Professional Med J. 2017; 24 (2): 293-295.

3. Levinson BA, Rapuano CJ, Cohen EJ, Hammersmith KM, Ayres BD, Laibson PR. Referrals to the Wills eye institute cornea service after laser in situ keratomileusis: reasons for patient dissatisfaction. J Cataract Refract Surg. 2008; 34: 3239.

4. Toda I. Dry eye after LASIK. Invest Ophthalmol Vis Sci. 2018; 1; 59 (14): 109-115.

5. Wimalasundera S. Computer vision syndrome. Galle Med J. 2009; 11: 25-29.

6. Gjerdrum B, Gundersen KG, Lundmark PO, Potvin R, Aakre BM. Prevalence of signs and symptoms of dry eye disease 5 to 15 after refractive surgery. Clin Ophthalmol. 2020; 14: 269-279.

7. Solomon R, Donnenfeld ED, Perry HD. The effects of LASIK on the ocular surface. Ocul Surf. 2004; 2 (1): 34-44.
8. Messmer ME. The pathophysiology, diagnosis, and treatment of dry eye disease. Dtsch Arztebl Int. 2015; 112 (5): 71-82.

9. Kymionis GD, Bouzoukis DI, Diakonis VF, Siganos C. Treatment of chronic dry eye: focus on cyclosporine. Clin Ophthalmol. 2008; 2 (4): 829-836.

10. Peyman GA, Sanders DR, Batlle JF, Féliz R, Cabrera G. Cyclosporine $0.05 \%$ ophthalmic preparation to aid recovery from loss of corneal sensitivity after LASIK. J Refract Surg. 2008; 24 (4): 337-343.

11. Miller KL, Walt JG, Mink DR, Hoang SS, Wilson SE, Perry HD, et al. Minimal clinically important difference for the ocular surface disease index. Arch Ophthalmol. 2010; 128 (1): 94-101.

12. Toda I. LASIK and the ocular surface. Cornea, 2008; 27 (Suppl. 1): 70-76.

13. Albietz JM, Lenton LM, McLennan SG. Dry eye after LASIK: comparison of outcomes for Asian and Caucasian eyes. Clin Exp Optom. 2005; 88 (2): 89-96.

14. Shoja MR, Besharati MR. Dry eye after LASIK for myopia: incidence and risk factors. Eur J Ophthalmol. 2007; 17 (1): 1-6.

15. Nassaralla BA, McLeod SD, Nassaralla JJ Jr. Effect of myopic LASIK on human corneal sensitivity. Ophthalmology, 2003; 110 (3): 497-502.

16. De Paiva CS, Chen Z, Koch DD, Hamill MB, Manual FK, Hassan SS, et al. The incidence and risk factors for developing dry eye after myopic LASIK. Am J Ophthalmol. 2006; 141: 438-445.

17. Donnenfeld ED, Solomon K, Perry HD, Doshi SJ, Ehrenhaus M, Solomon R, et al. The effect of hinge position on corneal sensation and dry eye after LASIK. Ophthalmology, 2003; 110 (5): 1023-1029.

18. Feng YF, Yu JG, Wang DD, Li JH, Huang JH, Shi JL, et al. The effect of hinge location on corneal sensation and dry eye after LASIK: a systematic review and meta-analysis. Graefes Arch Clin Exp Ophthalmol. 2013; 251 (1): 357-366.

19. Lee KW, Joo CK. Clinical results of laser in situ keratomileusis with superior and nasal hinges. J Cataract Refract Surg. 2003; 29 (3): 457-461.

20. Nassaralla BA, McLeod SD, Boteon JE, Nassaralla JJ Jr. The effect of hinge position and depth plate on the rate of recovery of corneal sensation following LASIK. Am J Ophthalmol. 2005; 139 (1): 118-124.

21. Kang KW, Kim HK. Efficacy of topical cyclosporine in mild dry eye patients having refractive surgery. J Korean Ophthalmol Soc. 2014; 55 (12): 1752-1757.

22. Torricelli AA, Santhiago MR, Wilson SE. Topical cyclosporine a treatment in corneal refractive surgery and patients with dry eye. J Refract Surg. 2014; 30 (8): 558-564. 
23. Kanellopoulos AJ. Incidence and management of symptomatic dry eye related to LASIK for myopia, with topical cyclosporine A. Clin Ophthalmol. 2019; 13: $545-552$.

24. Salib GM, McDonald MB, Smolek M. Safety and efficacy of cyclosporine $0.05 \%$ drops versus unpreserved artificial tears in dry-eye patients having laser in situ keratomileusis. J Cataract Refract Surg. 2006; 32 (5): 772-778.

25. Ursea R, Purcell TL, Tan BU, Nalgirkar A, Lovaton ME, Ehrenhaus MR, et al. The effect of cyclosporine A (Restasis) on recovery of visual acuity following LASIK. J Refract Surg. 2008; 24 (5): 473-476.

\section{Authors' Designation and Contribution}

Muhammad Saeed Iqbal; Professor and Head of Department: Concepts, Design, Manuscript preparation, Manuscript editing, Manuscript review.

Kanwal Latif; Assistant Professor: Literature research, Data acquisition, Data analysis, Statistical analysis, Manuscript preparation.

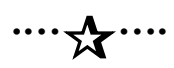

